\title{
Inclusão digital como invenção do quotidiano: um estudo de caso*
}

\author{
Marcelo El Khouri Buzato \\ Universidade Federal da Grande Dourados, Faculdade de Comunicação, Artes e Letras \\ Universidade Estadual de Campinas, Programa de Pós-Graduação em Lingüística Aplicada
}

\section{Introdução}

Este trabalho tem por propósito apresentar resumidamente os resultados de um estudo de caso exploratório vinculado à minha pesquisa em inclusão digital, realizada no âmbito do programa de doutorado em linguística aplicada do Instituto de Estudos da Linguagem da Universidade Estadual de Campinas (IEL-UNICAMP). Na seção introdutória, apresento os principais pressupostos teórico-metodológicos que nortearam tal estudo, como forma de contextualizar as perguntas de pesquisa utilizadas, assim como o tratamento dos dados obtidos e a discussão dos resultados. Na seção intermediária, são apresentados sucintamente as perguntas, os pressupostos, os sujeitos e o contexto da pesquisa, seguidos por quatro subseções temáticas que aglutinam os dados obtidos e discussões sobre eles. Finalizando o trabalho, ofereço ao leitor algumas considerações sobre implicações dos resultados da

* Este trabalho foi realizado com o apoio do UOL (www. uol.com.br), através do Programa UOL Bolsa Pesquisa, processo número 20060509140453a. pesquisa e da abordagem teórico-metodológica a ser utilizada em futuros estudos que busquem relacionar inclusão digital e educação.

\section{Uma perspectiva para a inclusão digital}

Tomar a palavra inclusão como forma de delimitar o tema deste trabalho não foi uma decisão fácil. Necessito fazê-lo porque se trata do termo mais utilizado hoje para descrever um objetivo ou ideal que expressões como cidadania, dignidade ou justiça social talvez descrevessem melhor, se não estivessem desgastadas pela hipocrisia do nosso dia-a-dia. Utilizar inclusão, portanto, dá a possibilidade de obter mais interlocutores; por isso o fiz.

$\mathrm{Na}$ maior parte dos casos, porém, quem fala em inclusão fala do lugar de incluído, isto é, fala como alguém que se entende como pertencente a um contexto estável e homogêneo no qual o objetivo ou ideal que aqueles termos desgastados descrevem teria sido plenamente alcançado, alguém que já definiu aquilo que é, tem ou faz como o bom e necessário para todos, e que está disposto a trazer para esse mesmo espaço o 
“excluído", isto é, aquele que, por influência do destino, da natureza, da tradição, de seus próprios hábitos, da sua própria ignorância ou de alguma fatalidade histórica, não "adentrou" tal condição.

Nesse sentido, "inclusão" desliza para o sentido de hegemonia, isto é, para um processo de subordinação de significados, valores, crenças de grupos subalternos aos de uma classe superior, por meio da direção e do consenso. Inclusão digital, por conseguinte, denotaria uma faceta desse processo relacionada às tecnologias que são fundamentais para a manutenção e ampliação dessa hegemonia. Penso, porém, que a palavra inclusão não tem necessariamente que adquirir esses sentidos. É possível, talvez crucial, para quem ainda acredita que conceitos como cidadania, dignidade e justiça social, mesmo mudando de sentido, não perderam sua relevância, falar de inclusão a partir de uma outra perspectiva.

Dessa outra perspectiva, inclusão e exclusão não são sinônimos de "estar dentro" e "estar fora", partilhar do consenso ou alienar-se: são dois modos simultâneos de estar no mundo. Trata-se de uma perspectiva baseada na heterogeneidade (da linguagem, da cultura, do sujeito e da tecnologia) a partir da qual é possível perceber que somos sempre iguais e diferentes dos outros, que estamos sempre incluídos e excluídos ao mesmo tempo: inclusão, então, seria a possibilidade de subversão das relações de poder e das formas de opressão que se nutrem e se perpetuam por meio da homogeneização, da padronização, da imposição de necessidades de alguns a todos e do fechamento dos significados das novas tecnologias da comunicação e da informação (doravante, TIC) em função de tais necessidades.

Essa concepção de inclusão digital apresenta-se como especialmente significativa quando temos em mente as periferias dos grandes centros urbanos que começam a ser "conectadas" por meio de telefones celulares e centros comunitários de acesso à internet; isto é, quando pensamos em processos de inclusão não como a aplicação da racionalidade (crítica) a formas politicamente organizadas de reprodução/normalização ou conscientização/resistência relacionadas às TIC, mas como um processo criativo, conflituoso e até certo ponto autogerido de apropriação e "enunciação" dessas tecnologias.

\section{Inclusão digital como invenção do quotidiano}

A busca de uma fundamentação teórico-metodológica para a pesquisa em inclusão digital nessa perspectiva particular levou-me à abordagem de Certeau (1994) para a inserção do homem ordinário nas estruturas de poder e de suas operações no campo disciplinar de uma economia escriturística. A visão de inclusão digital que me orienta se alinha com a sociologia do quotidiano de Certeau porque em ambos os casos não se supõe o indivíduo como elemento autônomo cujas vontades e capacidades determinariam sua condição social, nem se crê num indivíduo como um termo determinado de relações sociais determinantes, mas busca-se identificar formas e possibilidades de agentividade, isto é, maneiras pelas quais sujeitos subalternos produzem, sob aparência de sujeição e conformidade e dentro de um sistema disciplinar que não podem ignorar, formas de inclusão que não se igualam à padronização e às formas de diferenciação que não implicam o isolamento.

Da extensa e complexa rede de conceitos utilizados por Certeau (1994), destaco três pares especialmente relevantes para esta pesquisa: a) produtores e consumidores; b) estratégias e táticas; c) lugar e espaço.

O autor classifica como produtores grupos ou classes de indivíduos capazes de criar, impor e manter espaços disciplinares e prescrever formas de ordenamento e representação sociais. Concretamente, estariam entre os produtores os governos, as corporações de negócios, os poderes judiciários, as instâncias de planejamento urbano, as elites acadêmicas, os fornecedores de serviços públicos, as corporações profissionais e assim por diante. Entre os consumidores estariam todos aqueles constrangidos a viver (supostamente) de acordo com as formas de ordenamento e disciplina prescritas pelos produtores e por meio dos produtos (físicos e simbólicos) que lhes são impostos.

As palavras produtor e consumidor não devem ser interpretadas binariamente, como se apenas os produ- 
tores produzissem e como se os consumidores apenas assimilassem pacificamente o que lhes é imposto. A diferença entre produtores e consumidores não é uma diferença entre quem produz e quem não produz, mas entre quem produz de forma centralizada, racionalizada, expansionista e estratégica e quem o faz de forma astuciosa, dispersa e tática, pelas maneiras de empregar os produtos impostos pela ordem dominante. O produto dos consumidores é o uso que fazem dos discursos, artefatos, commodities, bens simbólicos, instalações e ordenamentos produzidos pelos produtores. Vale ressaltar que produtor e consumidor são papéis relativos, isto é, em uma sociedade complexa como a nossa, produtores em uma determinada rede de relações são sempre consumidores em outras, e vice-versa.

Certeau (1994) vai buscar essa noção de uso como produção na problemática do enunciado em lingüística. Comprar e caminhar, ler e habitar, falar e cozinhar, vistos no contexto da ação, são operações, formas de atualizar as possibilidades de um sistema, maneiras de apropriar-se e inserir-se em uma rede de relações, assim como enunciar é uma forma de apropriar-se da língua e implantar um interlocutor e um contrato relacional. Assim sendo, investigar a invenção do quotidiano é inventariar e relacionar essas operações nos âmbitos das diversas práticas que põem em contato produtores e consumidores por meio de suas produções.

Estratégia e tática são conceitos de que o autor lança mão para descrever as relações de força que caracterizam a produção como imposição ou como uso nas práticas quotidianas. Por estratégia Certeau (1994, p. 99) concebe "o cálculo (ou manipulação) das relações de força que se torna possível a partir do momento em que um sujeito de querer e poder (uma empresa, um exército, uma cidade, uma instituição científica) pode ser isolado". Estratégia é, assim, a ação autônoma do forte sobre um espaço que lhe é próprio ou propriamente delimitado.

Tática é, por sua vez, a arte do fraco que se realiza no espaço do forte, é algo que aproveita falhas na vigilância para defletir a influência das estratégias. Seu poder está justamente na imprevisibilidade. Usos e táticas, contudo, não são sinônimos de resistência, pois a formulação da estratégia é, em geral, uma resposta aos usos e táticas, isto é, usos e táticas freqüentemente definem os contornos e limites das estratégias e não o contrário, como no caso da resistência pura e simples.

Para Certeau (1994, p. 201) um lugar é “a ordem (seja qual for) segundo a qual se distribuem elementos nas relações de coexistência [...], uma configuração instantânea de posições. Implica uma indicação de estabilidade". Espaço é "o efeito produzido pelas operações que o orientam, circunstanciam-no, temporalizam-no e o levam a funcionar em unidade polivalente de programas conflituais ou de proximidades contratuais". Retomando o problema da enunciação como modelo, Certeau (1994, p. 202) explica que "o espaço estaria para o lugar como a palavra quando falada, isto é, quando é percebida na ambigüidade de uma efetuação, mudada em um termo que depende de múltiplas convenções, colocada como o ato de um presente (ou de um tempo), e modificado pelas transformações devidas a proximidades sucessivas". Em suma: "o espaço é um lugar praticado".

Por meio desse quadro conceitual, podemos pensar na inclusão digital como um jogo de estratégia e tática, um jogo no qual produtores implementam as TIC como estratégia capaz de ampliar o seu lugar para além dos limites (territoriais, institucionais) tradicionais de seu poder, ao passo que consumidores, circunstancializando tal lugar, usando as TIC, produzem um espaço, fazem existir, "multiforme embora sub-reptícia ou reprimida, uma outra experiência que não é a da passividade" (Certeau, 1994, p. 268).

\section{Letramentos digitais}

O usuário da linguagem digital e de dispositivos digitais (como computador, telefone celular ou aparelho de TV digital), como qualquer leitor, não é um mero consumidor. Ele pratica essa linguagem e esses dispositivos, lança mão daquilo que Certeau (1994) chama de usos e táticas para apropriar-se do que lhe é dado a ler (em sentido amplo) de maneiras peculiares, por vezes transgressivas, irônicas ou poéticas. Ao fazê-lo, entretanto, ele lança mão de scripts, recursos 
interativos e modelos interpretativos culturalmente compartilhados, aos quais chamamos letramentos (Barton, 1994). Quando tais práticas estão atreladas ao uso de computadores (ou outros dispositivos digitais), estamos diante do que boa parte da literatura denomina letramentos digitais. E quando diante de letramentos (digitais ou não), estamos em posição de observar mecanismos de inclusão/exclusão (digital ou não), uma vez que tais práticas são fortemente relacionadas a formas de opressão (ou emancipação) e reprodução (ou transformação) sociais nas economias escriturísticas (e agora digitalizadas) em que vivemos.

Letramentos digitais, contudo, não são simplesmente letramentos convencionais transpostos para novas condições técnicas de mediação (assim como um website não é simplesmente uma página de livro transposta para a tela, tampouco a "sociedade em rede" é a sociedade industrial da era moderna simplesmente transposta para uma nova infra-estrutura técnico-econômica). Letramentos digitais são redes complexas de letramentos (práticas sociais) que se apóiam, entrelaçam, contestam e modificam mútua e continuamente nas e por meio, virtude ou influência das TIC (Buzato, 2007), e que o fazem diferentemente em contextos culturais e situacionais diferentes.

Assim, descrever, correlacionar e problematizar letramentos digitais é não apenas uma forma de mapear a inclusão digital, mas também de fortalecer sua concepção fundada na heterogeneidade, na emancipação e na agentividade, em detrimento daquelas fundadas na padronização, conformação e subalternidade. É nesse sentido que o arcabouço teórico-metodológico aqui exposto (inclusive o conceito de letramento) foi aplicado ao estudo de caso apresentado resumidamente a seguir.

\section{Inclusão digital na Casa Brasil Água e Vida: um estudo de caso}

\section{Paradigma e método}

Este estudo insere-se no paradigma qualitativointerpretativo e na tradição etnometodológica dos estudos de letramento (Coulon, 1995). Na perspectiva qualitativo-interpretativa, trabalha-se com a idéia de que a atividade humana é fundamentalmente uma experiência social em que se está constantemente elaborando significados, e busca-se reconstruir essa experiência e ter acesso a esses significados por meio da observação e da participação nas práticas sociais que se deseja compreender.

Aplicados a esse paradigma, estudos de caso exploratórios buscam sobretudo levantar hipóteses e perguntas relevantes que possam orientar futuras pesquisas. São, em geral, conduzidos como preparação para estudos mais aprofundados ou de maiores dimensões sobre aquele mesmo conjunto de fenômenos (Yin, 1984), como é o propósito do trabalho aqui apresentado.

\section{Pressupostos e perguntas de pesquisa}

Para a concepção inicial deste estudo, foram considerados os seguintes pressupostos:

1. A inclusão digital, em qualquer contexto, será marcada simultaneamente por apropriações e conflitos relacionados às TIC.

2. Os sujeitos que praticam as TIC em um telecentro podem ser vistos como produtores e consumidores. Os produtores desse lugar (seus idealizadores, financiadores e administradores) criam uma estratégia de inclusão que pode ser traduzida na forma de um sistema disciplinar. Os consumidores (pessoas "atendidas" pelo projeto) defletem e subvertem essa estratégia por meio de usos e táticas, as quais por sua vez podem constituir formas de inclusão digital não previstas e eventualmente não desejadas pelos produtores, mas que têm potencial para a transformação das relações de hegemonia-subalternidade.

Tendo em vista esses pressupostos, o estudo busca responder às seguintes perguntas:

1. Como uma comunidade considerada "excluída" se apropria das TIC nas suas práticas quotidianas em um telecentro? 
2. Em que medida e de que maneiras essas apropriações reproduzem ou subvertem padrões ou expectativas dos produtores do projeto?

3. Quais são os conflitos relacionados a essa apropriação?

4. Que letramentos são praticados no centro comunitário e de que maneiras estão relacionados entre si e com tais apropriações e conflitos?

\section{Tratamento dos dados}

Os dados que compõem este estudo foram obtidos ao longo de cinco visitas à Casa Brasil Água e Vida (doravante CBAV), nos meses de outubro e novembro de 2006, por meio de:

a) observações não-participantes de uma sessão de "uso livre" de aproximadamente uma hora e de uma aula do curso de introdução em informática, com duração de duas horas;

b) entrevista casual, não estruturada, com uma voluntária do telecentro e coleta de depoimentos de diversos usuários do serviço de "uso livre";

c) duas entrevistas em profundidade com o coordenador do projeto, uma não estruturada, no início da pesquisa, e uma quase-estruturada, após a preparação do esboço dos resultados.

As notas de campo colhidas durante várias visitas à CBAV e a dois outros telecentros (nas cidades de São Paulo e Campinas) complementam os dados. Foram consideradas ainda mensagens eletrônicas trocadas com um implementador social do Governo Eletrônico - Serviço de Atendimento ao Cidadão (GESAC) ${ }^{1}$ antes e depois de tais visitas.

Os períodos de observação, assim como as entrevistas, foram gravados em áudio na íntegra. Realizada

${ }^{1}$ O programa GESAC, do governo federal, tem como meta disponibilizar acesso à internet a comunidades consideradas "excluídas" em todo o território nacional, preferencialmente por meio de antenas de conexão via satélite, assim como um conjunto de serviços e ferramentas tecnológicas. uma "leitura" vertical dessas gravações, identifiquei núcleos temáticos com base nos quais os arquivos de áudio foram posteriormente segmentados e correlacionados. Para sistematizar a análise desses núcleos, defini as seguintes categorias analíticas: apropriações; estratégias, usos e táticas; conflitos; e letramento.

Procurei aplicar essas categorias à identificação de como os sujeitos que contribuíram para a pesquisa elaboram o significado da inclusão digital tal qual ela se dá no seu mundo social mais imediato, e então relacionar tais interpretações ao arcabouço teóricometodológico exposto na parte inicial deste artigo.

\section{Contexto do estudo}

Instalada na periferia de Guarulhos, em região densamente povoada (aproximadamente 220.000 pessoas), mas de baixíssimo índice de desenvolvimento humano, a CBAV é uma organização não-governamental que congrega diversas iniciativas de desenvolvimento comunitário, tanto de forma autônoma como por meio de parcerias com entidades governamentais (por exemplo: o Programa Saúde da Família, programas educacionais em meio aberto e programas de alfabetização de adultos). Entre os projetos existentes na entidade está um telecentro, obtido por meio do projeto Casa Brasil, uma iniciativa do governo federal que reúne diversos ministérios, órgãos públicos e empresas estatais sob a coordenação do Instituto Nacional de Tecnologia da Informação (ITI). ${ }^{2}$

O telecentro ali instalado dispõe de 20 microcomputadores conectados à internet nos quais estão instalados exclusivamente o sistema operacional Linux e diversos aplicativos de código aberto. Neles são desenvolvidos, basicamente, três tipos de atividades: uso livre, cursos de introdução à informática e oficinas especializadas.

Os freqüentadores do uso livre podem utilizar os computadores durante uma hora por dia, necessitando

\footnotetext{
${ }^{2}$ Mais informações sobre o programa Casa Brasil podem ser obtidas na página eletrônica do ITI em http://www.iti.br/twiki/bin/ view/Casabrasil/WebHome.
} 
em geral reservar tal horário com antecedência, em virtude da grande procura por essas vagas. Não há monitoramento severo das atividades realizadas pelos usuários, havendo apenas a orientação para que os freqüentadores não acessem conteúdos inadequados, como sites dedicados a pornografia, jogos de azar, racismo, apologia ao ódio e à violência etc.

Nos cursos de introdução à informática, que no caso aqui descrito duram 20 horas, com sessões diárias de duas horas de aula, os freqüentadores familiarizamse com conceitos básicos da informática (software e hardware, software livre e software proprietário etc.) e com aplicativos de uso mais freqüente, como processadores de texto, planilhas de cálculo, programas de edição de imagens e navegadores de internet.

As oficinas especializadas podem estar relacionadas tanto à produção de conteúdo multimídia (websites, animação gráfica, edição de áudio/vídeo) quanto à programação de computadores ou ao desenvolvimento de sistemas aplicativos. Há ainda, esporadicamente, oficinas de "metarreciclagem", nas quais os participantes aprendem a montar computadores reciclados a partir de partes de computadores velhos doadas por empresas. À época deste estudo, não havia em curso nenhuma oficina especializada na CBAV, razão pela qual tal modalidade não será descrita ou analisada.

A CBAV é freqüentada por pessoas de diversas faixas etárias, algumas das quais residem a distâncias consideráveis da casa. A maioria dos freqüentadores, entretanto, é composta por jovens em idade escolar e adultos desempregados em busca de qualificação profissional. Há também donas de casa e idosos que procuram o telecentro para fazer o curso de introdução à informática ou para acompanhar seus filhos nos horários de uso livre.

\section{Os sujeitos}

S., o coordenador, é um homem de 45 anos, que reside em um bairro mais central e de perfil socioeconômico mais alto no município do Guarulhos. Com formação profissional e experiência corporativa de 20 anos na área de informática, já possuiu uma pequena empresa de serviços daquele tipo. Juntou-se ao projeto um ano antes da realização deste estudo por uma decisão pessoal, de foro íntimo, que o motivou a "transferir esse conhecimento" para um projeto de inclusão. É responsável pelo projeto desde seu início, e o desenvolveu sob a orientação dos implementadores sociais designados pelo governo federal.

A. é uma voluntária treinada por S. para ministrar cursos de introdução à informática. Com 18 anos de idade à época, cursava o último ano do ensino médio. Freqüentadora da CBAV desde a infância, foi eleita para o conselho gestor da Casa Brasil. não tem formação específica na área de informática além da que obteve no próprio curso oferecido pelo telecentro.

T., estudante de 14 anos, é freqüentadora assídua do uso livre, ao qual chega por volta das $13 \mathrm{~h} 00$, imediatamente após sair da escola. Quando a abordei, durante minha observação de uma sessão de uso livre, estava utilizando o site de relacionamentos Orkut $^{3}$ e, ao mesmo tempo, interagindo via $\mathrm{MSN}^{4}$ com uma amiga.

P. é um jovem jogador profissional de futebol, aparentando não mais do que 20 anos. Quando o abordei, estava consultando um site especializado em esportes, no qual quis me mostrar os resultados dos jogos dos quais participara no ano anterior por uma equipe do interior do estado de São Paulo.

E. é uma estudante egressa do ensino médio, aparentando 20 anos, que encontrei preenchendo o

${ }^{3} \mathrm{O}$ Orkut é um website de relacionamentos pertencente à companhia Google. Leva o nome de seu projetista-chefe, Orkut Büyükkokten, engenheiro de nacionalidade turca. A particularidade que fez do Orkut um grande sucesso é que só se pode tornar membro de suas comunidades virtuais o usuário que receber um convite de outro usuário já cadastrado.

4 MSN ou Microsoft Service Network é um conjunto de serviços oferecidos pela Microsoft, empresa produtora do sistema operacional Windows, que permite a comunicação síncrona por meio de texto, voz e imagem através da internet. A sigla designa, informalmente, um programa de mensagens instantâneas muito popular entre os usuários da internet. 
formulário eletrônico de inscrição para o vestibular de uma universidade privada. Informou utilizar o telecentro apenas porque seu computador doméstico estava quebrado no momento.

Dona T., 38 anos, dona de casa, e seu filho W., 10 anos, estudante do ensino fundamental, vinham ao telecentro juntos. Durante uma sessão de uso livre da qual participei, dona T. pediu-me ajuda para acessar o website de um programa de TV de cunho religioso do qual era expectadora assídua. Disse que seu filho, que geralmente a auxilia, tinha sido designado para a outra sala. De fato, W. encontrava-se na sala ao lado, consultando o serviço de busca de imagens do Google.

\section{Síntese dos resultados e discussão}

Sobre as apropriações

Empresto de Rodriguez (2006, p. 38; itálicos adicionados) a definição de apropriação como

[...] a capacidade de tomar para si, de assimilar e, ampliando um pouco mais esta concepção, de compreender e transformar, estabelecendo quais usos o objeto apropriado pode ter e quais são os efeitos que este uso acarretará para si e para o grupo. É um movimento que acontece em um processo dinâmico, que pode envolver momentos de adaptação e reinvenção de significados.

A noção de que a apropriação é um processo dinâmico parece estar incorporada às três modalidades de acesso oferecidas na CBAV. Nos cursos de introdução, busca-se fomentar os estágios iniciais, de assimilação e compreensão das TIC naquela população. Nas oficinas, procura-se diversificar e aprofundar o conhecimento sobre os usos que as TIC podem ter, e estimular a sua aplicação na produção de artefatos e competências que possam tornar-se formas de ganhar a vida ou de melhorá-la. No uso livre, o que se pretende é dar à comunidade a oportunidade de utilizar o computador e a internet de forma autônoma, para que se apropriem de recursos úteis para a sua participação ativa, crítica e cidadã.
S. relatou como evidências de apropriação das TIC pela comunidade casos de pessoas que conseguiram, por intermédio do curso de introdução à informática, ingressar no mercado de trabalho. Há, por exemplo, uma jovem entregadora de panfletos que, tendo feito o curso de informática, passou a coordenar o trabalho dos colegas, lotada no escritório, junto a seu empregador. Esse exemplo parece sumarizar uma das interpretações vigentes na comunidade acerca dos usos que o computador pode ter e dos efeitos desses usos em suas vidas: uma possibilidade concreta de melhoria nas condições de vida a partir de alguma proposta ou oportunidade profissional, na qual o domínio das TIC entra como precondição.

Para as pessoas que procuram o telecentro sem um propósito profissional ou educacional definido, $\mathrm{S}$. diz ser necessário promover uma "conscientização" inicial. Na sua visão,

\section{[...] isso é uma cultura muito relacionada com o formato de educação que é dado no Brasil. Por que é que a pessoa não dá continuidade às coisas? Porque ela não foi formada para isso [...]. Eu diria que em torno de uns $40 \%$ fazem o curso muitas vezes por fazer... Porque ainda não se situaram no mundo mercadológico. Mas uma boa parte faz, então uns... uns $60 \%$ fazem já definindo que é aquilo que ele quer, que ele precisa daquilo.}

Pode-se afirmar, portanto, que os produtores da CBAV, representados por S., interpretam como inclusão apropriações das TIC que levam à inserção do sujeito nas relações de produção e consumo já estabelecidas, à sua absorção pelo mercado de trabalho. Ao mesmo tempo, consideram fator-chave para tanto que o sujeito se engaje em um conflito consigo mesmo, contra os hábitos, disposições pessoais ou perfis culturais, que, na sua visão, necessitam ser modificados.

Talvez por essa razão S. não considere relevante (para a inclusão) boa parte das práticas que observei nas sessões de uso livre. Essas formas de apropriação podem ser resumidas, com base em minhas observações na CBAV (e outros telecentros), a alguns padrões, dentro os quais se destacam: 
a) realização de trabalhos escolares;

b) redação de currículos e o preenchimento de fichas de cadastro em agências de emprego on-line;

c) prática de jogos on-line;

d) consulta a sites relacionados a programas de televisão;

e) uso do site de relacionamentos Orkut;

f) uso do comunicador instantâneo MSN Messenger ou programas de $e$-mail.

Em princípio, esses padrões não parecem refletir formas de transformação ou reinvenção de significados das TIC. De fato, em muitos casos, o que se nota neles é uma atitude meramente responsiva a certas demandas de setores hegemônicos (canais comerciais de televisão, empregadores etc.). S. relatou, nesse sentido, o caso exemplar de uma senhora que procurou o telecentro na expectativa de poder obter receitas culinárias do site de uma apresentadora de programas femininos na TV. ${ }^{5}$

Quando se contextualizam melhor esses padrões de uso, entretanto, aparecem nuances de uma apropriação mais criativa e crítica das TIC. P., o jogador de futebol, por exemplo, revela que o significado da internet em sua vida é conscientemente definido. Tratase de uma maneira de buscar informações relativas ao seu projeto profissional que não estão disponíveis em outras fontes. Jogador profissional de um pequeno time do interior do estado, p. não aparece nos programas ou páginas de esportes da TV ou dos jornais locais, mas encontra na world wide web (www) uma maneira de contabilizar seus resultados, avaliar suas possibilidades futuras e demonstrar à família e aos amigos - e até a estranhos como eu - a concretização de seu "sonho" de ser jogador profissional. Sem um empresário que represente seus interesses ou que

\footnotetext{
${ }^{5}$ Essa influência da televisão (e de outras mídias tradicionais)
} na apropriação das TIC pela comunidade está também documentada por Rojas et al. (2004), no seu estudo em uma comunidade de imigrantes mexicanos nos Estados Unidos, entre outros estudos. promova sua imagem, ele apropriou-se da internet de forma estratégica, como quer S., mas não de forma meramente responsiva a uma pressão ou oportunidade externa. Ele a usa para construir a sua história, narrarse a si mesmo, registrar uma trajetória de vida que, por enquanto, não interessa às páginas esportivas ou aos programas de TV.

Embora boa parte dos adolescentes utilize o comunicador instantâneo no telecentro para "bater papo", às vezes com amigos que estão dentro do mesmo laboratório, uma senhora relatou ter aprendido a utilizar o comunicador instantâneo para poder estar em contato com seu filho, empregado numa indústria japonesa e residente naquele país. Aqui a apropriação também obedece a uma motivação externa - o custo dos interurbanos, a distância imposta entre mãe e filho por conta do encolhimento do mercado de trabalho no país etc. -, mas resulta numa transformação da espaçotemporalidade a que a senhora estava até então subordinada. As TIC entram na sua vida estrategicamente, como uma maneira de fazer entrelaçarem-se em seu quotidiano tempos-espaços até então incompatíveis. Esse é também, certamente, um dos significados do Orkut para os adolescentes do centro: romper com circunstâncias espaço-temporais que circunscrevem e disciplinam formas de interagir que são importantes na construção de suas identidades e no fortalecimento de suas redes de relações afetivas.

E., a pré-universitária, ao contrário de p. e dos orkuteiros, parece encaixar-se perfeitamente no que S., o coordenador, descreve como um uso inclusivo. Seu caso, porém, parece apenas ilustrar um dado que estudos como os de Rojas et al. (2004) e Snyder, Angus e Sutherland-Smith (2002) trazem: não foram as TIC que a levaram a conceber o aumento de seu "capital cultural" como uma estratégia de inclusão; foi sua participação num determinado tipo de capital cultural (estudante pré-universitária de classe média) que a trouxe, forçosa e seletivamente, às TIC. Assim, E. não utiliza as TIC para incluir-se, mas porque já está incluída, no sentido de inclusão que parece nortear as interpretações de $\mathrm{S}$.

Entretanto, nenhuma das apropriações aqui relata- 
das é mais significativa, do ponto de vista da agentividade e da subversão de expectativas do que a maneira como W. utilizava o buscador de imagens do Google. Aqui, o que normalmente se poderia descrever como uma apropriação assimilativa é que o usuário buscasse no site representações de um objeto, pessoa ou conceito, determinado por uma palavra-chave específica, para ilustrar, ornamentar ou complementar um texto (observei que assim procediam jovens que faziam pesquisas escolares naquele e em outros locais). Quando abordei W., porém, ele acabara de fazer uma busca de imagens utilizando como palavra-chave a frase "carros envenenadíssimos". Entre as imagens obtidas, selecionava as que mais lhe agradavam, e, clicando sobre elas, descobria o nome do carro em questão. Em nova busca de imagens, utilizando agora o nome de um carro específico (naquele dia, utilizou a frase "sobre o Zonda"), obtinha imagens detalhadas de diversos ângulos e partes específicas do automóvel, desenhos técnicos, gráficos de desempenho, e assim por diante.

É interessante notar que, caso tivesse feito a mesma consulta no buscador textual, como fiz eu mesmo mais tarde, encontraria, misturadas às do carro, informações sobre um tipo de vento que assola periodicamente a Argentina e sobre um freqüentador de um fórum de discussão cujo sobrenome é Zonda, entre outras. W., então, parece ter compreendido o potencial do buscador de imagens para desenvolver um tipo específico de pesquisa que, diferentemente da que é pedida pela escola normalmente, combina fruição estética e conhecimento técnico/factual altamente sofisticado a partir de um interesse pessoal próprio. Além disso, percebeu o melhor potencial do buscador de imagens em relação ao textual, para a desambiguação do tipo de informação pertinente; assim transformou o buscador de imagens numa espécie de enciclopédia visual ad hoc.

Esses exemplos parecem sugerir que a intervenção pedagógica dos produtores não é necessariamente uma precondição para uma apropriação mais transformadora das TIC, embora, é claro, possa instrumentalizála. Em verdade, no próprio discurso de S. a idéia de transformação é controversa, muitas vezes assume o sentido de conformação ou submissão. Por essa razão, decidi observar como se dava essa intervenção durante uma aula do curso de introdução à informática para adultos, conduzida por A.

S. deu início à aula apresentando-me aos participantes como uma pessoa que veio da universidade para conhecer o telecentro. Em seguida, pediu aos alunos que se apresentassem, e a mim. Passando o "comando" da aula para A., fechou sua participação com o seguinte comentário:

Aproveitem, comecem a fazer amizade [...]. Quando a gente estiver falando de mercado de trabalho, que envolve a parte de currículo e tudo mais, a gente vai falar sobre isso aqui, ó (anota a palavra networking no quadro). Gravem isso! Se vocês puderem, na casa de vocês, pesquisem o que significa isso aqui ó: néti uorkin ${ }^{6} ;$ a gente vai falar um pouco sobre isso. Isto aqui vai ser a chave das oportunidades que vocês podem ter na vida profissional.

A. nasceu e foi criada na comunidade, tendo freqüentado o local, como criança assistida, por muitos anos. Segundo ela mesma, minha presença a deixara um tanto desconfortável (por ser eu um professor), pois se sentia ainda um tanto quanto insegura na posição de instrutora, que acabara de assumir. Notei desde o início que, naquele evento, diferentemente do uso livre, vigorava uma espécie de script escolar. A. assumira um tom "professoral", postada à frente dos alunos adultos, junto a um quadro-negro:

\section{A.: Agora nós iremos trabalhar com a área de désqui tópi.}

Quem sabe o que é?

${ }^{6}$ Utiliza-se a partir deste ponto formas ortográficas alternativas ao português escrito padrão que visam ilustrar nuances e flutuações fonológicas nas falas registradas, indicativas de processos de assimilação e transformação da palavra alheia no discurso dos sujeitos participantes. Optou-se por não utilizar transcrições fonéticas para facilitar o acesso a tais nuances e flutuações por leitores não familiarizados com esse tipo de notação, uma vez que os trechos citados não são objeto de análise lingüística propriamente dita. 
Aluno: Désqui quem?

A.: Dêsq tópi (anota a palavra "desktop" no quadro).

Aluno: Désqui... Ali é um "k"?

A.: É. Dêsq tópi.

Aluno: Sinceramente, na minha época que eu estudei... (Meneia a cabeça.)

A.: É essa telinha que vocês "tão" vendo aí... Significa "área de trabalho". Na área de désqui topi, nós iremos aprender a abrir janelas e a criar pastas. Quem sabe abrir uma janela? Aluno: Eu! (Abre a janela da sala provocando risos.)

Esse pequeno excerto, representativo de todo o evento, mostra que A. e os participantes se apropriaram da estrutura discursiva "iniciação-resposta-avaliação", típica da escola (Sinclair \& Coulthard, 1975), para construir sua situação de ensino-aprendizagem. A maneira como A. utilizava o quadro para representar esquematicamente a interface do computador, as anotações feitas pelos participantes em pequenos cadernos escolares, o plano de aula preparado por S. e seguido à risca por A., enfim, todos esses elementos indicam essa apropriação, e ajudam a encaixar essa instância de uso do telecentro na estratégia "pedagógica" que S. revelou.

Mas a brincadeira do aluno junto à janela, a forma vacilante como A. pronunciava a palavra desktop, o discurso inicial de S. sobre networking, todos esses usos da linguagem que observei parecem evidenciar também que, naquele contexto, o foco da apropriação é mais amplo do que o computador enquanto "ferramenta”. Para pôr em prática sua visão estratégica de inclusão digital, S. quer que a comunidade adquira um conceito do mundo dos negócios, algo que fizera sentido na sua própria experiência pessoal (S. conseguiu emprego na CBAV por intermédio de um amigo). É improvável que as pessoas da comunidade desconheçam o conceito em si, isto é, a noção de que ter uma rede de contatos sociais ajuda na busca de emprego. Mas S. pretende "conscientizar" os participantes de que ampliar e manter essa rede é uma estratégia da qual devem lançar mão. A palavra que vem de fora (dos manuais de job-hunting, dos seminários de negócios etc.) entra no plano de $\mathrm{S}$. como uma forma de iluminar esse outro significado, estratégico, das relações sociais de vizinhança, amizade, compadrio etc. existentes na comunidade, uma forma de "conscientizar" a comunidade de seu valor estratégico.

A. e o aluno junto à janela parecem estar igualmente tentando apropriar-se de novos significantes (Como se escreve? Como se pronuncia?) para velhos significados (a tela, a área de trabalho) e novos significados para velhos significantes (o que querem dizer "janela", "gabinete", "pasta" etc., agora?), mas não da maneira estratégica, como quer S. O que se vê atuar aí é uma apropriação tática, um processo de vernacularização que não constitui exatamente uma forma de resistência, mas de refração daquilo que vem de fora por meio de usos táticos, criativos, imprevistos da linguagem. Assim, o que S. gostaria, estrategicamente, de ver florescer na comunidade está de fato florescendo, mas não necessariamente sob seu controle. As pessoas buscam ativamente decifrar as TIC, mas decifrá-las segundo seus próprios códigos, por meio de scripts conhecidos ou por meio de outros códigos e scripts que, entretanto, não correspondem às expectativas de S. Afinal, não seria exatamente networking o que os orkuteiros do uso livre mais fazem?

T., por exemplo, participava de mais de uma centena de comunidades no Orkut, pelas quais dizia ter feito inúmeras novas amizades. Sem que S. notasse, expandia sua rede de contatos muito além das quatro paredes do laboratório, mas não necessariamente com a finalidade de conseguir um emprego. Entre as comunidades de que T. participava, havia, por exemplo, duas que reuniam canhotos que, como ela, enfrentam problemas de acessibilidade numa sociedade totalmente orientada para as necessidades dos destros. Por essas comunidades, T. não apenas expandia e cultivava relações que, mais tarde, poderiam vir a ser úteis, mas especialmente se engajava, aqui e agora, na luta pelo reconhecimento de uma das diferenças que a constituem como sujeito. Assim, T. apropriara-se do Orkut (um objeto não previsto) de forma não prevista, mas com isso realizava o tipo de engajamento crítico consigo mesma que S. julgava fundamental para a sua inclusão. 


\section{Jogos de tática e estratégia}

A fundamentação oferecida por Certeau (1994) ajuda a prever que, em contraposição à forma centralizada, racionalizada e estratégica com que os produtores do telecentro tentam fomentar as apropriações, a comunidade o fará de forma astuciosa, dispersa e tática, com maneiras não previstas de empregar as TIC e o próprio projeto. Os dados parecem sugerir que é preciso ir além de uma segmentação binária entre tática e estratégia para fazer tal descrição, pois tanto S. quanto a comunidade utilizam o telecentro de forma tática e estratégica simultaneamente.

Colocado em posição especialmente delicada, entre as demandas dos patrocinadores e as dificuldades que caracterizam o quotidiano da comunidade, $\mathrm{S}$. tirava proveito do ordenamento imposto pelo próprio lugar (a própria arquitetura da casa), das formas de atividade prescritas pelos patrocinadores e das limitações práticas que lhe eram impostas (a quantidade de equipamentos, os limites orçamentários, a proibição da comercialização de qualquer serviço ou produto gerado pelo telecentro etc.) para produzir, de forma dispersa e não planejada, certos comportamentos que julgava positivos para o sucesso do projeto. Ele contou-me, por exemplo, que freqüentemente aproveitava a restrição ao número de folhas que podiam ser impressas para ensinar as pessoas a utilizar o editor de textos:

A gente sempre faz eles buscarem o seguinte recurso: copia... Seleciona o que você tem aí na tela do computador, abre o editor de texto, cola lá, daí você diminui o tamanho da letra [...] e daí eles começam a aprender, sem querer, como é que mexe com o editor de texto e essas coisas, pra poder economizar, entendeu?

De maneira semelhante, $\mathrm{S}$. aproveita as ocasiões em que os freqüentadores se deparam com a barreira lingüística do inglês em seus percursos de navegação na internet para ensiná-los a utilizar a ferramenta de tradução automática do Google ou ensina as crianças que têm dúvidas quanto à fidedignidade das fontes de pesquisa que encontram na internet a confrontar o conteúdo da fonte com o verbete correspondente na Wikipédia. ${ }^{7}$ Essas "dicas" de S., segundo me contou A., acabam sendo compartilhadas pelos usuários, que se ajudam mutuamente e terminam compensando a falta de diretrizes ou estratégias de aprendizagem que as escolas da região, em tese, deveriam fornecer àqueles jovens, mas, segundo S., não fornecem.

$\mathrm{O}$ depoimento de dona $\mathrm{T}$. também ilustra um interessante misto de tática e estratégia no uso das TIC e do telecentro. Não se sentindo identificada com o computador, ou seduzida por suas possibilidades de uso profissional, dona $\mathrm{T}$. usava o telecentro basicamente com dois propósitos: primeiro, para prolongar sua experiência televisual vinculada a um programa religioso, algo difícil de fazer em casa, ante as demandas de seu marido e seu filho por seus serviços e pelo uso da TV. Acompanhar o filho permitia-lhe, ao mesmo tempo, fazer seu papel de mãe e contornar as restrições domésticas à fruição de um determinado tipo de conteúdo que lhe era prazeroso. Além disso, de maneira estratégica, dona T. pretendia investigar o potencial das TIC (no caso, um site religioso) para ir incutindo cumulativamente nas convicções de W. o mesmo apego à religião que lhe dava conforto em um quotidiano cheio de restrições, algo que não conseguia fazer pela TV:

$$
\begin{aligned}
& \text { É que o mundo vai se modificando cada vez mais, cada } \\
& \text { vez mais, cada vez mais, a tecnologia vai aumentando cada } \\
& \text { vez mais, mas falta o principal. [...] Ele (refere-se a W.) vai } \\
& \text { aprender tudo, ele vai ser um doutor, mas ali, ali vai faltar o } \\
& \text { principal. [...] Eu sinto necessidade de passar para ele quem } \\
& \text { é Deus, porque se não... }
\end{aligned}
$$

Em suma, tal qual S., dona T tem certas convicções sobre inclusão, e tenta aplicar as TIC de forma

7 Wikipédia é uma enciclopédia multilíngüe on-line construída colaborativamente por especialistas e pessoas "comuns" de diversas regiões do mundo, todas elas voluntárias. A consulta aos verbetes da Wikipédia é gratuita, e um engenhoso processo de verificação e revisão coletivas de seu conteúdo garante certa confiabilidade às informações que dela constam. 
estrategicamente vinculada a essas convicções. No entanto, tática e sub-repticiamente, boa parte dos sujeitos a quem ambos pretendem incluir já estão incluindo-se ou excluindo-se a si mesmos, à sua maneira, dentro e fora simultaneamente das estruturas, normas, scripts e convicções que lhes são impostas a despeito das TIC, ou por meio delas.

\section{Conflitos}

Conflitos são, ao mesmo tempo, parte do que os usuários do telecentro experimentam quando lá estão e parte do que procuram contornar lá estando. A., por exemplo, usa o telecentro taticamente nesse sentido. Porque tem uma irmã casada que dispõe de um computador e uma conexão em banda larga em sua casa, em tese A. não necessitaria freqüentar o telecentro. Quando perguntei se a informática fazia parte de seus planos profissionais futuros, respondeu-me que não, categoricamente. Seu trabalho voluntário no telecentro era, segundo ela mesma, uma maneira de manter-se em contato com pessoas e valores que foram muito importantes na sua infância, quando participou do projeto Cantinho Feliz (alimentação, recreação, reforço escolar e atividades artísticas para crianças das favelas da região, dos 4 aos 16 anos).

Eu completei a idade de sair. E quando eu estava saindo, começou a Casa Brasil.

A. tornou-se membro do conselho gestor, uma atividade que ao mesmo tempo estabelece um vínculo com a casa, e por meio da qual se afasta das brigas e da violência que marcam os outros lugares de convivência de que dispõe: casa, a escola, a rua.

A.: Aqui não tem "constritura".

Pesq.: Não tem o quê?

A.: Conflito.

Não é que a Casa Brasil seja um espaço livre de conflitos, explica A. Há casos de pais que invadem o telecentro para espancar seus filhos, por exemplo. A diferença é que, aproveitando a ordem institucional imposta pelo projeto, a experiência prática de participar de um conselho (no que se incluem scripts discursivos e procedurais úteis para a solução de polêmicas), A. encontrou uma oportunidade, assim como certas ferramentas, para lidar de forma mais produtiva com os muitos conflitos que a cercam. Fez daquele lugar um espaço e desse espaço um refúgio.

Mas mais interessante para a análise aqui proposta do que os pequenos conflitos que perpassam o quotidiano do telecentro é um conflito que poderíamos chamar "institucional", que aparece mais ou menos de forma explícita em praticamente todos os eventos que observei e registrei neste estudo: a relação entre o telecentro e as escolas da região.

Ao mesmo tempo em que parece haver uma estreita - embora não oficializada - conexão entre o telecentro e as escolas da região, seja na forma de tarefas escolares que constituem um dos padrões mais significativos de "uso livre", da apropriação de padrões discursivos e procedimentais típicos da escola pelos instrutores voluntários, seja pelo fato de que o telecentro funciona, do ponto de vista dos pais dos freqüentadores mais jovens, como um prolongamento espaço-temporal da escola (em oposição à casa ou à rua), há também desconexões significativas entre essas duas instâncias de prática, assim como pontos de tensão. Um desses pontos aparece de forma mais explícita na crítica de $\mathrm{S}$. à maneira como certas escolas lidam com o acesso de seus alunos às TIC:

Alguns alunos dizem que os professores não deixam os alunos terem acesso, porque eles vão quebrar o computador. Por outro lado, outros dizem também que não tem ninguém pra ficar acompanhando, pra ficar dando o devido suporte às crianças. Outros dizem que utilizam uma vez por mês, e tudo mais. Parece que a coisa ainda ta meio deficiente, não tá... Não tá legal.

Na visão de S., inclusão digital e educação formal são intimamente interligadas, antes de mais nada, pela questão do letramento (S. não utiliza o termo, mas remete-se diversas vezes ao conceito). No caso de 
muitas pessoas da comunidade, o fracasso da escolarização não impede que se apropriem das TIC por meio da CBAV, mas limita sensivelmente o potencial criativo e crítico dessa apropriação.

Tem criança da sétima série que não sabe ler e escrever... Que está estudando em escola estadual. [...] Aí você tem que conciliar a vontade dela, o querer dela [...] com essas dificuldades. Aí o que nós fazemos? Ela entra e fica brincando, quer dizer, ela vem pro acesso livre, e nós sugerimos alguns sites pra que ela possa estar desenvolvendo a leitura, desenvolvendo a matemática, se desenvolvendo..., né?

S., entretanto, acredita na escola como agência de inclusão, e utiliza sua posição de liderança de forma condizente com essa crença. Presenciei, mais de uma vez, eventos em que admoestava crianças freqüentadoras do uso livre para saber se estariam ou não em horário de aula, se haviam terminado as tarefas escolares que vieram executar no telecentro antes de conectarem-se ao Orkut e assim por diante. Talvez por isso mesmo, tenha um interesse especial, e crítico, pelas atividades escolares que os jovens trazem ao telecentro.

Uma vez uma menina falou aqui que a professora pediu... como trabalho de escola, o resumo da novela das oito. Eu falei: "Tem certeza?", ela falou: "Tenho", "Por incrível que pareça ela me pediu isso". [...] Eu falei assim: "Não é a sua tia, não, que ta pedindo o resumo?". Ela me provou por A mais B que era trabalho mesmo. Então, eles pedem umas coisas absurdas, sabe, umas coisas que a gente não entende dentro do contexto histórico mundial, nacional, é..., "cidadal", "bairral” [risos], sabe, umas coisas que não dá pra entender por que que o professor pediu aquilo.

Obviamente não se pode aferir, por esse depoimento, a validade do trabalho feito pelas escolas da região. Mesmo no caso específico mencionado por S., seria preciso conhecer o contexto em que se inseria a tarefa. Por exemplo, a professora poderia estar trabalhando o "gênero" resumo ou tentando discutir as formas de transposição de uma narrativa audiovi- sual para a escrita. O ponto mais significativo desse excerto, contudo, não é a adequação ou não da tarefa, mas o fato de que $\mathrm{S}$. e seus voluntários, assim como os professores da escola, estão em posição de influir na configuração da rede de letramentos que os sujeitos ou a comunidade constroem para si. É dessa rede que W. trouxe as "palavras-chave" que o ajudaram a construir um novo script de pesquisa, baseado no buscador de imagens, ou que A. e seus alunos trouxeram mecanismos discursivos que lhes permitem fazer funcionar o curso de introdução à informática (mesmo sem um "professor" no sentido lato), e é provavelmente de letramentos que praticam no telecentro que os jovens da comunidade levarão para a escola outras questões, linguagens e modos de lidar com o texto. Contudo, ao menos nesse caso, escola e telecentro não estão correntemente em condição de colaborar estratégica e conscientemente entre si para a configuração e o fortalecimento dessa rede.

Não se trata, obviamente, de um conflito de valores ou interesses, pois telecentro e escola compartilham, basicamente, o objetivo da inclusão daqueles sujeitos (seja qual for a concepção de inclusão utilizada) por meio de práticas educativas. Talvez se trate de um conflito de prioridades, isto é, o acesso, no caso do telecentro, ou certas precondições consideradas indispensáveis ao acesso, mas ainda não contempladas, no caso da escola. Os letramentos digitais, como procuro mostrar a seguir, constituem um lócus especialmente revelador desse conflito, mas também um tema inspirador de uma nova postura, mais cooperativa, nas relações entre diferentes produtores engajados na inclusão digital dos mesmos consumidores.

\section{Letramentos}

Destaco, nesta seção, não propriamente os padrões ou diferentes letramentos que observei existir naquele contexto (em alguma medida já abordados nas seções anteriores), mas a maneira como certos letramentos digitais ali existentes apontam para uma concepção de inclusão digital fundada na transformação, na agentividade e na subversão de mecanismos 
de ampliação e reforço de certas hierarquias de poder que, em última análise, são produtoras da exclusão. Trata-se de uma seleção restrita, mas, creio, extremamente significativa do sentido exploratório do estudo em questão - e do seu potencial para a geração de novas perguntas e temas de pesquisa.

\section{Pegando receitas no site do programa de TV}

S. relatou, um tanto decepcionado, o caso de uma senhora que viera à CBAV com o intuito de capacitarse a obter receitas culinárias no site de um programa dedicado ao público feminino em uma grande rede de TV aberta. Visitando o site em questão, descobri que, na seção dedicada à culinária, se encontram receitas apresentadas por escrito, na forma composicional que respeita a tradição daquele gênero (título, ingredientes, modo de preparo), mas há também clipes de vídeo digital que reproduzem o preparo da receita tal qual executado na TV. Junto a ambos, ferramentas de busca e recursos de indexação como uma caixa de seleção por título de receita e um menu de consulta por categorias (carnes, massas, saladas etc.), estão à disposição da telespectadora/internauta, recursos esses que são típicos também de outras interfaces da www que dão acesso a bancos de dados, como sites de bibliotecas, lojas virtuais, sites de serviços bancários ou governamentais etc.

Vemos, então, que se entrelaçam nesse website diferentes gêneros e linguagens, alguns familiares à potencial usuária do telecentro, outros nem tanto. Assim também se pode dizer dos letramentos envolvidos. Tradicionalmente, o telespectador de um programa culinário assiste a uma demonstração visual do preparo da receita enquanto anota, dentro do possível, os ingredientes e as quantidades utilizadas. Ao final dessa demonstração, o apresentador ou a apresentadora dita a receita, de modo quase ritual, a uma velocidade aquém da velocidade da fala usual, freqüentemente apoiado pelo texto correspondente exibido na tela da TV, enquanto o telespectador copia. Há, então, um script, uma seqüência habitual e uma série de estratégias adotadas pelo telespectador e pelo apresentador nessa prática; há aí, enfim, um "letramento televisivo".

Quando o "ditado culinário" é abolido da TV e substituído pela receita disponibilizada no site, duas mudanças importantes ocorrem. Primeiro, a demonstração visual desvincula-se, no tempo-espaço, do registro escrito. Segundo, abre-se para o telespectador/ internauta a possibilidade de obter uma cópia pronta da receita. Para obtê-la, contudo, ele lança mão de outros letramentos (localizar um site, acionar um clipe de mídia dentro do navegador, imprimir um texto eletrônico de forma econômica etc.), adota um outro script: não é necessário ter lápis e papel à mão, não é necessário sincronizar-se com a TV. Pode-se encaixar o programa no tempo do internauta, pode-se desvincular o "saber fazer o prato" do tempo e da voz do apresentador ou da apresentadora.

Isso contesta o papel de espectador a que a fã do programa estava limitada, e, logo, vai de encontro ao que supostamente desejam seus produtores, isto é, que os telespectadores permaneçam vinculados a esse tempo e a essa voz o máximo possível, pois nisso se traduz a "audiência" que lhes é tão cara. Se os produtores do programa o fazem com tamanha confiança, é porque esses letramentos não ameaçam aquilo que de fato consideram seu trunfo: o fato de que eles escolhem o prato e a forma como o prato é encenado naquele cenário cuidadosamente preparado, por aquelas pessoas cuidadosamente escolhidas para estar em frente às câmeras naquele momento específico do dia.

Esse fato cria uma situação que ilustra de maneira bastante simples a problemática da inclusão digital entre apropriações responsivas e transformadoras. Ao mesmo tempo em que contestam relações de poder tradicionais (emissor/criador-receptor/reprodutor), esses outros letramentos do telespectador/internauta são fundamentais para que o programa de TV possa enfrentar seus próprios desafios, como a introdução do controle remoto - que faz da monotonia de um "ditado culinário" um risco - ou a necessidade de cativar o público jovem (a menina-futura-dona de casa enquanto categoria demográfica), cujos hábitos de consumo de mídia guardam um lugar cada vez menor para a TV 
e cada vez maior para a internet. Em contrapartida, podemos supor, de forma otimista, que a familiaridade com ferramentas de busca e categorização na $w w w$ eventualmente encoraje nossa dona de casa a procurar outras receitas, sabores, fontes de informação, tipos de prática ou maneiras de ser mulher que não as definidas pela emissora e pelo(a) apresentador(a) em questão. É com fé nessa segunda possibilidade que $\mathrm{S}$. e os produtores do telecentro trabalham incessantemente para a ampliação do acesso às TIC, mas é principalmente pela escola que deveríamos criar as condições de sustentar tal transição, antes, durante e depois do acesso.

\section{Pesquisando na www}

Tanto quanto a TV, pode-se culpar a escola por boa parte das apropriações assimilativas observadas no telecentro. O tipo mais freqüente de tarefa escolar ali realizado é a pesquisa escolar na $w w w$. Em geral, os jovens trazem para a sessão de uso livre um tema ou palavra-chave definido pelo professor, o qual, lançado no site de buscas, na enciclopédia colaborativa Wikipédia, ou eventualmente em algum site especializado, fornece ao jovem textos relativos ao tema, textos que, então, são impressos (na totalidade ou em parte), de acordo com a disponibilidade limitada de papel e toner. O próximo passo é elaborar em casa, com base naquele(s) texto(s), um manuscrito que será entregue ao professor. Perguntei a A. se não seria mais lógico elaborar esse texto final no processador de textos e imprimi-lo para entregar ao professor. Ela disse-me que boa parte dos seus professores não aceita textos digitados no computador, por acreditarem que o texto manuscrito atesta que o aluno "trabalhou", em lugar de apenas copiar e colar.

Aqui, como no caso da televisão, temos letramentos que se complementam ao mesmo tempo em que se contestam. Da escola, vem o velho script: receber tema do professor, localizar fonte, transcrever conteúdo da fonte "nas próprias palavras", devolver ao professor. Subjacente a esse script estão as crenças de que o conhecimento está disponível em algum repositório externo e de que o aprendizado se dá por meio do esforço de recontá-lo nas próprias palavras. Contraposta a esse script está a maneira de pesquisar do menino W. Partindo de um interesse próprio, algo que tem sentido pessoal e valor simbólico em sua vida (mesmo que concretamente esteja muito longe de sua realidade), W. transita entre sistemas de representação e ferramentas de pesquisa diferentes para obter suas próprias palavras-chave. A partir delas, vai construindo representações mentais mais complexas e abrangentes, que geram novos temas e novas palavras-chave de seu interesse. W. não imprime, cataloga ou sequer anota os nomes dos carros e suas particularidades ou as Uniform Resource Locators (URLs) visitadas, pois sabe que pode recuperá-los quando quiser, utilizando as mesmas palavras-chave. Estas ele guarda como índices mentais que levam a conteúdos constantemente renovados, expandidos e complexificados na própria rede. Em suma: seu trabalho não é contar o que está na $w w w$ em suas próprias palavras: é buscar na $w w w$, por meios diversos, as palavras que contam para ele!

Quando confrontamos esse exemplo com o da dona de casa, salta aos olhos novamente o papel crucial da escola. Naquele caso, o de instrumentalizar o sujeito para o salto, a transição entre práticas e posturas acríticas e responsivas diante do texto (seja de que natureza for); neste, o de acolher e nutrir práticas e posturas como as do menino W. e de fortalecê-las e disseminá-las ao longo do próprio processo educativo, assim como o da formação de seus professores.

\section{Construindo identidades com o Orkut}

Criar, manter, pesquisar e aderir a comunidades no Orkut é um dos letramentos mais significativos no telecentro, em especial entre freqüentadores mais jovens. Já me referi à manutenção e à expansão de laços sociais e à construção de espaço-temporalidades alternativas como um dos sentidos dessa prática, mas falta ainda o papel desse letramento na construção das identidades pessoais dos jovens freqüentadores do telecentro.

Se para entrar no Orkut é necessário conhecer alguém que já esteja lá, para efetivamente estar no 
Orkut é preciso construir e manter um "perfil”, isto é, uma página eletrônica dentro do programa pela qual o orkuteiro pode ser identificado. O perfil é um pequeno texto em que o usuário se apresenta "por escrito", acompanhado de sua foto, links para as comunidades a que está filiado (no site) e para perfis de usuários do site que são considerados seus amigos. Pode-se também disponibilizar, abaixo da apresentação pessoal, uma extensa lista de características, gostos ou traços de personalidade do titular: seu estado civil, aniversário, línguas que domina, religião, e assim por diante.

Além dessas informações geradas/escolhidas pelo próprio titular, a página resume certos dados numéricos a partir dos quais é possível inferir a popularidade ou o status social do usuário na rede de relacionamentos do site. Há um link que contabiliza seu número de fãs, isto é, usuários que se declararam admiradores do titular da página, e outro que contabiliza seus scraps - mensagens deixadas por outros usuários por meio de um mecanismo de comunicação assíncrona denominado scrap book (álbum de recortes, na tradução literal). Apesar do nome, os usuários utilizam o scrap book mais como um mural público no qual trocam recados ou contam novidades (note-se que essas mensagens estão abertas para a leitura de qualquer usuário).

Feita essa pequena descrição do funcionamento do site, posso então retomar o uso do Orkut como letramento digital vinculado a um certo tipo de construção identitária ou "narrativa do Eu". Sem pretender abordar a relação entre letramento e identidade de forma mais abrangente ou profunda do que o necessário, basta-me considerar, como Hall (2005, p. 13), que a identidade é "formada e transformada continuamente em relação às formas pelas quais somos representados ou interpelados nos sistemas culturais que nos rodeiam". Collins e Blot (2004, p. 105), por sua vez, registram que "escolhas entre múltiplas variantes de linguagem permitem às pessoas habitar uma multiplicidade de identidades que se sobrepassam" e que "discursos fornecem posições do sujeito, habilitando certas identidades e se opondo ou desabilitando outras”. Há, portanto, uma conexão dinâmica entre linguagem e identidade e, conseqüentemente, entre certos letramentos, sejam eles impostos ou autogerados (Barton, 1994), e as identidades (etária, profissional, de gênero, étnica, de classe etc.) que se entrecruzam na constituição móvel dos sujeitos.

O uso do Orkut pelo jovem freqüentador do telecentro encaixa-se de duas maneiras nesse quadro mais geral da relação entre identidade e letramento. Antes de mais nada, enquanto prática simbólica, habilita sua identidade jovem-urbano-conectado, posiciona-o como construtor de uma nova sociabilidade e uma nova relação com o tempo-espaço, diferente daquela da qual participam seus pais e professores. Nessa construção, note-se, o bloguês ou orkutês ${ }^{8}$ - enquanto escolha de uma variante de linguagem - é bastante significativo. Mas o Orkut permite/demanda também que o sujeito se encaixe em uma estrutura categorizada de atributos predefinidos (pela lista que faz parte do perfil do usuário), de relações "ranqueadas" e contabilizadas com outros usuários (amigo, amigo do peito, fã etc.), e de temas das comunidades. A filiação a esses temas/ comunidades fornece mais do que assuntos de interesse: funciona como narrativa biográfica ("estudei no Maria Imaculada", "Nasci de novo", "Fui demitido", "Tocava a campainha e corria", "Já me jogaram na piscina" etc.), fornece asserções sobre si mesmo ("Sou canhoto", "Adoro minha mãe", "Eu bebo sim", “Odeio lavar louça", "Eu sou fiel" etc.) e projeta formas de reagir a/interagir com o outro ("F***-se quem me odeia", "Cala a boca e beija logo", "Conta comigo", "Sou assim e não vou mudar" etc.).

Em linha com o que ocorre na busca de receitas culinárias, há aqui também letramentos que se apóiam e se contestam simultaneamente. Estar no Orkut é certamente forma de ser e estar além do quotidiano definido institucionalmente pela escola, pela família e pelo próprio telecentro. Mas adicionar um vizinho, primo ou irmão na lista de amigos do Orkut, participar

8 Bloguês ou orkutês é o nome comumente associado à variedade não-padrão de português escrito utilizada por usuários do Orkut e outras ferramentas de comunicação mediada por computador. 
da comunidade "Estudo(ei) na escola X" e assim por diante, são obviamente formas de continuar a ser e estar "local". Talvez por isso boa parte das mensagens deixadas nos scrap books tenham uma função muito menos informativa do que, digamos, fática. Retomam gêneros primários do convívio quotidiano ("e $a i$ nanyy... kuanto tempo heimm...", "Oi, $\mathrm{Na}$, adorei sua visita la em casa, volte sempre, hein???", "aff vc saiu ou me block?"), sinalizam a mera presença ou disponibilidade do familiar, testam a continuidade ou não de outras conversas que vêm da vida off-line.

Se no caso das pesquisas escolares e das receitas culinárias ainda não está claro como esses letramentos repercutem na escola, no caso do Orkut o "vazamento" tem-se feito manifestar, de forma muito intensa e controversa, na polêmica do bloguês. Não pretendo aprofundar-me nessa análise, pois não disponho dos dados nem do espaço necessários para fazê-lo aqui, mas concluo esta seção apenas dizendo que o bloguês talvez seja parte do preço pago (pela escola) por aquela sua suposta opção estratégica de não priorizar o acesso, mas precondições supostamente indispensáveis ao acesso. Além disso, do ponto de vista da concepção estratégica de inclusão aqui pesquisada, tal polêmica talvez esteja mais mal situada no território do conhecimento ou não da norma padrão (como tem sido) do que estaria no terreno das construções identitárias viabilizadas ou bloqueadas pelas práticas escolares em tempos de globalização e sociedade em rede. Inclusive as da própria escola.

\section{Considerações finais}

Não pretendo afirmar que a abordagem teóricometodológica aqui utilizada seja mais válida ou eficiente que qualquer outra, tampouco que dos resultados obtidos a partir dela se possa prescrever qualquer tipo de ação ou concepção de inclusão digital que se pretenda absoluta. Procurei apenas narrar um esforço inicial no sentido da construção de uma abordagem coerente com uma certa concepção estratégica de inclusão, que tem a particularidade de enfatizar a agentividade dos sujeitos ditos "excluídos", uma agentividade que não se rende necessariamente a demandas sociais e tecnológicas que lhe seriam supostamente impostas pela marcha inexorável do progresso.

Desse esforço inicial, porém, resultam certas perguntas, mais profundas e complexas do que as aqui abordadas, que talvez possam inspirar outros estudos nos e entre os diferentes contextos em que se faz - ou se supõe fazer - inclusão digital, sejam eles institucionais (telecentro, escola, casa, trabalho, igreja etc.) ou demográficos (adolescentes, donas de casa, operários, professores etc.). Por exemplo, pode-se investigar os resultados das migrações, avaliações e intervenções recíprocas (por vezes colaborativas, por outras conflituosas) entre telecentros e escolas, à medida que os letramentos praticados por sujeitos que transitam entre esses contextos se vão entrelaçando. Pode-se também tentar compreender como a apropriação criativa e crítica das TIC que produtores de projetos como a Casa Brasil desejam fomentar nas comunidades repercutirá (ou não) numa apropriação mais crítica e criativa da própria escolarização, de seus recursos e discursos. Em sentido oposto, há que se investigar maneiras pelas quais estratégias pedagógicas mais transformadoras, fundamentadas nos princípios da educação crítica e em abordagens colaborativas ou na pedagogia de projetos, poderiam ser levadas da escola para os telecentros que começam a florescer por todo o país. Mas, mais do que gerar perguntas, a utilidade da abordagem aqui sugerida reside na possibilidade de trazer os assim chamados "excluídos” para a posição de sujeitos (e não objetos) da sua própria "inclusão", pelo reconhecimento de que os usos das TIC são formas de sua produção (e não apenas de seu consumo).

Isso não significa, obviamente, que tal olhar teórico-metodológico dispense revisões e desenvolvimentos. Marcus (1993, p. 4-6), por exemplo, aponta que hoje a configuração particular de quotidiano que embasava a pesquisa de Michel de Certeau e seus colaboradores pode ser "mais uma fantasia nostálgica do que um referente mais ou menos acurado da realidade na qual a integridade desse cronotropo depende", isto é, está cada vez mais evidente a noção de um quotidiano pós-moderno no qual "ações localizadas, 
delimitadas no tempo-espaço, aqui-e-agora como sítios simbólicos ou essenciais do cotidiano - a casa, o local de trabalho, a rua etc. - são cada vez mais vistas como histórias muito parciais".

Assim, embora a idéia de que os grupos subalternos produzem seu quotidiano (e não apenas são produzidos por ele) permaneça válida, a delimitação dele não pode mais ser pensada em termos de um espaço geográfico absoluto (algo significativo, por exemplo, para compreendermos a centralidade do Orkut na vida dos frequientadores da CBAV). A compressão do espaço-tempo, a dinâmica intercultural, a voracidade dos fluxos de informação, produtos, pessoas e formas simbólicas típicos da sociedade em rede (e da globalização) são fatores que os investigadores têm, cada vez mais, que considerar.

Nesse sentido, torna-se indispensável o desenvolvimento de procedimentos e instrumentos empíricos que respondam adequadamente à desterritorialização e à policontextualidade das práticas digitais, assim como de formas de representação (textual) dos resultados mais multidimensionais, multivocais e dialógicas do que as que tradicionalmente se produzem em estudos como o aqui resumido. Reside aí certamente uma oportunidade para pensarmos criticamente nossos próprios quotidianos de pesquisa/academia e maneiras de "reinventar" as TIC nesse sentido.

\section{Referências bibliográficas}

BARTON, David. Literacy: an introduction to the ecology of written language. Oxford: Blackwell, 1994.

BUZATO, Marcelo El Khouri. Entre a fronteira e a periferia: linguagem e letramento na inclusão digital. Tese (Doutorado em Lingüística Aplicada) - Instituto de Estudos da Linguagem, Universidade Estadual de Campinas, Campinas, 2007.

CERTEAU, Michael de. A invenção do cotidiano: artes de fazer. Trad. Ephraim Ferreira Alves. 8. ed. Petrópolis: Vozes, 1994. COLLINS, James; BLOT, Richard. Literacy and literacies: texts, power and identity. New York: Cambridge University Press, 2004. COULON, Alain. Etnometodologia e educação. Trad. Roberto Leal Ferreira. Petrópolis: Vozes, 1995.
HALL, Stuart. A identidade cultural na pós-modernidade. Rio de Janeiro: DP\&A, 2005.

MARCUS, George E. Everything, everywhere: the effacement of the scene of the everyday. Série Antropologia, UNB, n. 151, 1993. Disponível em: <http://www.unb.br/ics/dan/Serie151empdf.pdf>. Acesso em: 1 fev. 2006.

RODRIGUEZ, Carla Lopes. O movimento de apropriação das tecnologias de informação e comunicação (TIC) por adultos escolarizados em exercício de sua profissão: um estudo com agentes comunitários de saúde. Dissertação (Mestrado em Multimeios) - Instituto de Artes, Universidade Estadual de Campinas, Campinas, 2006.

ROJAS, Viviana; STRAUBHAAR, Joseph; FUENTES-BAUTISTA, Marta; PINON, Juan. Still divided: ethnicity, generation, cultural capital and new technologies. In: JAMBEIRO, Othon; STRAUBHAAR, Joseph (Orgs.). Informação e comunicação: o local e o global em Austin e Salvador. Salvador: EDUFBA, 2004. p. 297-322.

SINCLAIR, John McHardy; COULTHARD, Malcolm. Towards an analysis of discourse: the English used by teachers and pupils. London: OUP, 1975.

SNYDER, Ilana; ANGUS, Lawrie; SUTHERLAND-SMITH, Wendy. Building equitable literate futures: home and school computer-mediated literacy practices and disadvantage. Cambridge Journal of Education, n. 32, v. 3, p. 368-83, nov. 2002.

YIN, Robert. Case study research: design and methods. Newbury Park: Sage, 1984.

MARCELO EL KHOURI BUZATO, doutor em lingüística aplicada pela Universidade Estadual de Campinas (UNICAMP), é professor da Faculdade de Comunicação, Artes e Letras na Universidade Federal da Grande Dourados. Publicações recentes: "Desafios empírico-metodológicos para a pesquisa em letramentos digitais" (Trabalhos em Lingüística Aplicada, v. 46, p. 45-62, jan./jun. 2007) e "Sobre a necessidade de letramento eletrônico na formação de professores: o caso Teresa" (In: CABRAL, Loni Grimm; SOUZA, Pedro de; LOPES, Ruth Vasconcelos; PAGOTTO, Emilio Gozze (Eds.). Lingüística e ensino: novas tecnologias. Blumenau: Nova Letra, 2001). Pesquisa em andamento: "Práticas fronteiriças na inclusão digital". E-mail: marcelo.buzato@gmail.com

Recebido em março de 2007 Aprovado em fevereiro de 2008 
de apropriação e enunciação das novas tecnologias da informação e da comunicação (TIC). Descreve as diferentes formas dessa apropriação, incluindo os conflitos nelas imbricados, a partir do estudo dos letramentos digitais ali reinantes. Conclui que certas apropriações são, ao mesmo tempo, viabilizadas por letramentos oriundos de outros contextos, especialmente da escola, e potencialmente viabilizadoras de outras experiências ante as TIC que não a da passividade ou da responsividade. Problematiza as relações entre escola e telecentro enquanto agentes de inclusão digital e sugere questões relativas a essa relação como temas de futuros estudos.

Palavras-chave: inclusão digital; letramento digital; alfabetização digital; educação inclusiva

Digital inclusion as the practice of everyday life

This is an abbreviated version of an exploratory case study conducted in a tele-centre on the outskirts of Guarulhos. Assumptions from Michel de Certeau's sociology of everyday life are used in the investigation of the ways of digital inclusion conceived as a process of appropriation and enunciation of the new information and communication technologies (ICTs). Different forms of such appropriation, including conflicts embedded in them, are described based on the digital literacies found in the context. The study concludes that certain appropriations are, at the same

Marcelo El Khouri Buzato

Inclusão digital como invenção do quotidiano: um estudo de caso

Versão resumida de um estudo de caso exploratório realizado em um telecentro na periferia da cidade de Guarulhos. Toma pressupostos da sociologia do quotidiano, de Michel de Certeau, para investigar os caminhos da inclusão digital concebida como um processo time, enabled by literacies brought from other contexts, specially the school, and potentially enable other experiences confronted by ICTs that go beyond passiveness or responsiveness. The relations between school and tele-centre, both seen as agents of digital inclusion, are problematised, and research questions pertaining to such relations are suggested for future studies. 
Key words: digital inclusion; digital literacies; inclusive education

\section{Inclusión digital como invención de} lo cotidiano

Versión resumida de un estudio de caso exploratorio realizado en un telecentro en la periferia de la ciudad de Guarulhos. Toma presuposiciones de la sociología del cotidiano, de Michel de Certeau, para investigar los caminos de la inclusión digital concebida como un proceso de apropiación y enunciación de las nuevas tecnologías de la información y de la comunicación (TIC).

Describe las diferentes formas de esa apropiación, incluyendo los conflictos en ellas imbricados, a partir del estudio de los letramientos digitales allí reinantes. Concluí que ciertas apropiaciones son, al mismo tiempo, viabilizadas por letramientos oriundos de otros contextos, especialmente de la escuela, y potencialmente viabilizadotas de otras experiencias frente a las TIC que no a de la pasividad o de la responsividade. Surgen problemas en las relaciones entre escuela y telecentro en cuanto agentes de inclusión digital y sugiere cuestiones relativas a esa relación como temas de futuros estudios.

Palabras clave: inclusión digital; letramiento digital; alfabetización digital; educación inclusiva 